\title{
Children Family Food Choice Motives among Parents of Healthy Weight and Overweight School- Aged: a Mixed Method Study
}

\author{
Martha J Nepper ${ }^{1}$ and Weiwen Chai ${ }^{2 *}$ \\ ${ }^{1}$ Nebraska Methodist Health System, 8111 Dodge Street, Omaha, NE 68114, US \\ ${ }^{2}$ Department of Nutrition and Health Sciences, University of Nebraska-Lincoln, $1700 \mathrm{~N}$ 35th Street, Lincoln, NE 68583, US
}

Received: October 18, 2017; Accepted: November 15, 2017; Published: November 21, 2017

*Corresponding author: Weiwen Chai, Department of Nutrition and Health Sciences, University of Nebraska-Lincoln, 1700 N 35th Street, Lincoln, NE 68583, US, Tel: 402-472-7822; Fax: 402-472-1587; E-mail: wchai2@unl.edu

\begin{abstract}
Objective: To identify and compare parental Food Choice Motives (FCM) between healthy weight and overweight/obese children.

Methods: The study used an explanatory sequential mixed methods design conducting quantitative survey followed by participant interviews. Forty parents of healthy weight children and 42 parents of overweight/obese children (6-17 years) completed FCM surveys in their homes (quantitative phase) followed by in depth interviews (qualitative phase) with a subsample of 25 parents of 11 healthy weight and 14 overweight/obese regarding FCM.

Results: Motives of food's taste and health value scored highest among all the parents. Mood (17.9 \pm 4.8 vs. $15.7 \pm 4.5, \mathrm{P}=0.03$ ) and weight control related motive scores $(15.9 \pm 3.9$ vs. $13.1 \pm 3.4$, $\mathrm{P}=0.001$ ) were higher among parents of overweight/obese children compared to parents of healthy weight children. During interviews, parents of both healthy weight and overweight/obese children had similar views regarding price, convenience in food preparation, children's taste preference and food familiarity as important FCM. Parents of overweight/obese children mentioned that lack of support from other family members influenced their FCM while this was not expressed by parents of healthy weight children.
\end{abstract}

Conclusions: parents considered food's health value as an important motive, they often traded healthy foods with unhealthy foods due to other factors such as price, convenience, familiarity, and children's taste preference. The results provide a further understanding of parental FCM.

Keywords: Food choice motives; healthy weight; overweight; children; parents

\section{Introduction}

Childhood obesity and its health consequences have become a major public health concern in the United States [1, 2]. Multiple factors contribute to children's eating behaviors and consequently the development or prevention of obesity $[3,4]$.Parent's food choice motives are important to examine since parents are seen as the nutritional gatekeeper and the key moderator that influences the provision of healthy foods to their children in the home [5-7]. In a study among 563 parents and children, participants ranked food's health value, food's natural content, and food's sensory appeal the highest among food choice motives [5]. Parents who reported the above motives as most important had children with higher intake of healthy foods and lower intake of unhealthy foods. In contrast, the food choice motive, convenience, was positively associated with a higher intake of unhealthy foods, suggesting that parents would choose these types of foods because they require little or no preparation [5]. Similarly, another study among 1,095 children ages 12-13 years and their parents showed that sensory appeal was the most important food choice motive, followed by food's health value, convenience in preparation, natural content of foods and foods that helped with weight control. Again, researchers found that the food choice motive of convenience was positively associated with children's intake of "junk" foods [8].

While it is important to identify the key food choice motives from parents and determine how they are associated with children's dietary intake, it is equally important to have a deep understanding about why parents have these motives, whether their actual decisions for what kind of foods (healthy or unhealthy) they purchase and provide to their children truly reflect the motives parents reported on the survey, and the other factors that influence parents' food choices. These questions cannot be fully answered without a qualitative approach to explore parents' perceptions on these issues. To our knowledge, no studies have used a mixed method approach which can provide a more complete picture in understanding parents' food choice motives when providing foods to their children in the home. Thus, in the current study we used a mixed method study design to: 1) identify parental food choice motives and compare these motives between parents of overweight/obese and parents of healthy weight children; and 2) explore parental views in depth to further understand what motivates parents to make choices when providing healthy or unhealthy foods to their children. 


\section{Methods}

\section{Study Design}

An explanatory sequential mixed methods design was used for this study. The study collected quantitative data first (quantitative phase) which was followed by in-depth qualitative data collection (qualitative phase). In the first, quantitative phase of the study, data were collected during in-home visits of healthy weight and overweight/obese school-aged children and the quantitative variable was parental food choice motives. The second, qualitative phase was conducted to further explain the quantitative results, which included individual interviews conducted with a subsample of parents to explore their perceptions of food choice motives when providing food for their children. This type of design provided a richer and more in-depth explanation of the quantitative results obtained. The study was approved by the University of Nebraska-Lincoln Institutional Review Board.

\section{Quantitative data collection}

\section{Study participants and procedures:}

Parents or primary caregivers and their children were recruited from communities in Lincoln, Omaha, and surrounding communities in Nebraska. Eligible criteria were parents/or primary caregivers $(\geq 19$ years and primarily responsible for household shopping and food preparation) with a school aged child between the ages of 6 and 17 years and fluent in English.). Home visits were conducted from May 2014 to May 2015 by the research team. During the home visit, parents completed a Family Food Choice Motives survey and a demographic questionnaire [9]. Children's weights and heights were measured with light clothing and no shoes using a weight scale and portable audiometer. Heights and weights were measured three times by researchers for accuracy, and if a measurement was the same for two or more times, this measurement was used. Body mass index (BMI) was calculated using Centers for Disease Control and Prevention guidelines and plotted on age/gender-specific growth charts. After measurements were taken, the child was placed in either the healthy weight or overweight/obese group, and no children were placed in the underweight category. Weight categories were defined as follow: $\geq 95$ th percentile as obese; between the 85 th and 95th percentile as overweight; and between the 5 th and 85 th percentile as healthy [10].Written consent was obtained from both the parents and children before data collection.

\section{Family food choice motive survey:}

The Food Choice Motive Survey developed by Steptoe, et al. was a commonly used instrument to measure family food choice motives [9]. The questionnaire was developed through factor analysis of responses from a sample of 358 adults aged from 18 to 87 years. Nine factors emerged, and were categorized into health, mood, convenience, sensory appeal, natural content, price, weight control, familiarity and ethical concern [9]. Since the original questionnaire by Steptoe, et al. was developed to measure the personal motives that underlie food choices of adults, it was modified by Roo, et al. to assess motives of foods chosen for the family [5]. The current study used the modified Food Choice Motive questionnaire with seven subscales (food's health value, food's natural content, foods for mood, sensory appeal, price and convenience, foods for weight control, and familiarity of the food). A 7-point Likert scale was used to score the responses of the participants, with 1 for "strongly disagree" to 7 for "strongly agree" [5]. We further categorized the responses into the following three categories: 1) "totally/mostly/somewhat disagree"; 2"neither agree nor disagree"; and 3) "totally/most/ somewhat agree".

\section{Data analysis:}

T-test was used to determine if any differences existed between healthy weight and overweight/obese children in family food choice motives. The items were grouped into seven subscales on the survey (food's health value, food's natural content, foods for mood, sensory appeal, price and convenience, foods for weight control, and familiarity of the food). The individual scores of the items in each subscale were summed to calculate the total score of the subscale. The analyses were repeated after adjusting for child's sex, family income $(<\$ 25,000 /$ year vs. $>\$ 25,000 /$ year), parental (the main food shopper/preparer) age and whether the parent (main food shopper/preparer) was working full time (yes vs. no), parental education (college graduate vs. no college graduate) and whether the child was from a single-parent household (yes vs. no). The results did not change materially after the adjustment for the aforementioned covariates (results not shown). SPSS version 23 (SPSS, Inc., Chicago, IL, USA) was used to perform all statistical analyses with a $P$ value of $<0.5$ considered statistically significant.

\section{Qualitative data collection: individual parent interviews}

\section{Participants and procedure:}

A subsample of parents who participated in the quantitative study phase was recruited during the in-home visit for an individual interview, which was conducted after the completion of the above quantitative surveys. Sample size was determined by the degree of data saturation, in which no new themes developed during the interviews. Written consent was obtained from the participants prior to the interviews.

Each interview was audio taped and took approximately 45 minutes to complete. The interview questions were modified from previously published studies and were pilot tested with four study participants for clarity and comprehension [11, 12]. Questions were then revised and a semi-structured interview format was used. Interviews occurred after quantitative data collection was completed. The interview began with a general knowledge question regarding how parents would define a healthy food and followed with questions on their food choice motives when providing foods to their children in the home. Each question included probing questions which elicited further 
detailed answers from the participants. Following are the interview questions:

1."What is your definition of a healthy food?"

2."Tell me about the sort of things that motivates what you buy at the grocery store and bring home to your children?"

3."Suppose your child has asked you to buy a food or beverage at the store that is not what you think he or she should eat or drink. How do you handle that situation?"

\section{Data analysis:}

All interviews were recorded, fully transcribed and analyzed by hand with data analysis and data collection occurring simultaneously by the investigators [13]. Each transcription was also independently analyzed and checked for accuracy by the second investigator, who listened to the audio and reviewed the transcription of the interviews. The preliminary exploratory analysis was used to gain a general overview of the data and to review data organization. Inductive data analysis was used to aggregate the text into codes and each code was used to develop into themes that reflected parents' perceptions of their food choice motives [13]. To validate the transcribed interviews, four participants were randomly selected to review the themes to determine if their views were adequately portrayed by the investigator. An expert in qualitative research (who was not associated with this project) reviewed the transcripts and developed themes independently from the research team. Any discrepancies in the themes were resolved and discussed among the qualitative expert and the research team.

\section{Results}

\section{Demographics}

Characteristics of the study participants are shown in Table 1 Quantitative phase included 82 parents and their children $(\mathrm{N}=82)$. The mean ages of the parents and children were 38.9 \pm 6.4 years and $9.8 \pm 2.6$ years, respectively. Forty-two of the children were overweight or obese (14 boys and 26 girls) and 40 were healthy weight ( 12 boys and 30 girls). The majority of the children in the study were White $(72 \%)$. The majority of the parents in the study was mothers (92\%) and lived with a spouse or another caregiver in the home (72\%). A total of $46 \%$ of the adult participants worked full time, 51\% graduated from college, and $23 \%$ of the families had an annual income less than $\$ 25,000$.

Table 1: Characteristics of study participants

\begin{tabular}{|c|c|c|c|c|}
\hline \multirow[b]{2}{*}{ Characteristics } & \multicolumn{2}{|c|}{ Quantitative phase } & \multicolumn{2}{|c|}{ Qualitative phase } \\
\hline & All participants & Healthy weight ${ }^{*}$ & Overweight/obese ${ }^{*}$ & All participants \\
\hline \multicolumn{5}{|l|}{ Children } \\
\hline $\mathrm{N}$ & 82 & 40 & 42 & 25 \\
\hline Age, year $($ mean \pm SD $)$ & $9.80 \pm 2.6$ & $9.4 \pm .4$ & $10.2 \pm .4$ & $9.6 \pm 1.6$ \\
\hline \multicolumn{5}{|l|}{ Sex, N (\%) } \\
\hline Boy & $26(31.7)$ & $14(35.0)$ & $12(28.6)$ & $8(32.0)$ \\
\hline Girl & $56(68.3)$ & $26(65.0)$ & $30(71.4)$ & $17(68.0)$ \\
\hline \multicolumn{5}{|l|}{ Race/ethnicity, N (\%) } \\
\hline White & $59(72.0)$ & $31(77.5)$ & $28(66.7)$ & $22(88.0)$ \\
\hline Black & $11(13.4)$ & $5(12.5)$ & $6(11.9)$ & $1(4.0)$ \\
\hline Hispanic & $9(11.0)$ & $4(10.0)$ & $5(14.3)$ & $1(4.0)$ \\
\hline Asian-American & $2(2.4)$ & $0(0.0)$ & $2(4.8)$ & $1(4.0)$ \\
\hline Other & $1(1.2)$ & $0(0.0)$ & $1(2.4)$ & $0(0)$ \\
\hline \multicolumn{5}{|l|}{ Weight status } \\
\hline Healthy weight & $40(48.7)$ & & & $14(56.0)$ \\
\hline Overweight/obese & $42(51,3)$ & & & $11(44.0)$ \\
\hline \multicolumn{5}{|l|}{ Parents/care giver } \\
\hline Age, year $($ mean $\pm S D)$ & $38.9 \pm 6.4$ & $36.8 \pm 5.9$ & $40.8 \pm 6.4$ & $39.0 \pm 7.6$ \\
\hline \multicolumn{5}{|l|}{ Sex, N (\%) } \\
\hline Male & $7(8.5)$ & $1(2.5)$ & $6(14.3)$ & $3(12.0)$ \\
\hline
\end{tabular}




\begin{tabular}{|c|c|c|c|c|}
\hline Female & $75(91.5)$ & $39(97.5)$ & $36(85.7)$ & $22(88.0)$ \\
\hline Family income, N (\%) & & & & $6(24.0)$ \\
\hline$<\$ 25,000 /$ year & $18(22.8)$ & $4(10.5)$ & $27(65.8)$ & $19(76.0)$ \\
\hline$\geq \$ 25,000 /$ year & $61(77.2)$ & $34(89.5)$ & $18(42.9)$ & $14(56 \%)$ \\
\hline College graduate & $42(51.2)$ & $24(60.0)$ & $26(61.9)$ & $11(44.0)$ \\
\hline Working full time, N (\%) & $37(45.7)$ & $11(28.2)$ & $18(42.9)$. & $6(25.0)$ \\
\hline $\begin{array}{c}\text { Single-parent household, N } \\
(\%)\end{array}$ & $23(28.0)$ & $5(12.5)$ & \\
\hline *Weight categories were defined: $\geq$ 95th percentile, obese; 85th - 94.99th, overweight; 5th- 84.99th percentile, healthy weight
\end{tabular}

A subsample of 25 parents (14 parents of healthy weight and 11 parents of overweight/obese children) were interviewed. The demographics of this subsample of parents were similar to that of the original sample involved in the quantitative data collection. The average age was $39.0 \pm 7.6$ years for the parents and $9.6 \pm$ 1.6 years for children. Approximately $56 \%$ of the parents had a college degree, $44 \%$ reported working full time and $25 \%$ were from single parent households. In addition, $24 \%$ of the households had an annual income below $\$ 25,000$. The majority of children were White (88\%) and 68\% were girls.

\section{Quantitative results}

The food choice motives that scored the highest among parents for both healthy weight and overweight/obese children (above $80 \%$ including those who responded "totally/mostly/somewhat agreed)were "tastes good" (100\%), "keeps us healthy" (97.6\%), "is nutritious" (97.6\%), "good value for our money" (91.5\%), "contains a lot of vitamins and minerals" (87.8\%), "smells nice"
(86.6\%), "looks nice" (85.3\%), "is not expensive" (83.0\%) and "contains natural ingredients" (82.5\%). Also, parents felt that the following food choice motives were important (scored between $58 \%$ and $70 \%$ ): "helps our family in weight control" (69.5\%), "contains no additives" (64.7\%), "(a food) is low in fat" (63.4\%), "cheers up our family" (63.5\%) and "takes no time to prepare" (58.5\%) Table 2.

Table 3 shows the scores of parental food choice motives between healthy weight and overweight/obese children. The food choice motive "contains a lot of vitamins and minerals" was scored higher for parents of healthy weight children $(6.13 \pm$ $0.88, \mathrm{P}=0.046)$ compared to overweight/obese children (5.88 \pm 1.38). The total scores of the subscales of mood related motives (overweight/obese, $17.93 \pm 4.79$; healthy weight, $15.70 \pm 4.54$; $\mathrm{p}=0.03$ ) and weight control related motives (overweight/obese, $15.90 \pm 3.91$; healthy weight, $13.10 \pm 3.42 ; \mathrm{p}=0.001$ ) were higher among parents of overweight/obese children compared to parents of healthy weight children.

Table 2: Frequency of participant responses to family food choice motives ( $\mathrm{N}=82$ )

\begin{tabular}{|c|c|}
\hline Family food choice Motives & $\mathbf{N}(\%)^{*}$ \\
\hline \multicolumn{2}{|l|}{ Keep us healthy } \\
\hline Totally/Most/Somewhat disagree & $1(1.2)$ \\
\hline Neither agree nor disagree & $1(1.2)$ \\
\hline Totally/Mostly/Somewhat agree & $80(97.6)$ \\
\hline \multicolumn{2}{|l|}{ Is nutritious } \\
\hline Totally/Most/Somewhat disagree & $2(2.4)$ \\
\hline Neither agree nor disagree & 0 \\
\hline Totally/Mostly/Somewhat agree & $80(97.6)$ \\
\hline \multicolumn{2}{|l|}{ Contains a lot vitamin/minerals } \\
\hline Totally/Most/Somewhat disagree & $2(2.4)$ \\
\hline Neither agree nor disagree & $8(9.8)$ \\
\hline Totally/Mostly/Somewhat agree & $72(87.8)$ \\
\hline \multicolumn{2}{|l|}{ Contains natural ingredients } \\
\hline Totally/Most/Some what dis agree & $5(6.1)$ \\
\hline Neither agree nor disagree & $11(13.4)$ \\
\hline Totally/Mostly/Somewhat agree & $66(82.5)$ \\
\hline
\end{tabular}




\begin{tabular}{|c|c|}
\hline \multicolumn{2}{|l|}{ Contains no additives } \\
\hline Totally/Most/Somewhat disagree & $9(11.0)$ \\
\hline Neither agree nor disagree & $20(24.4)$ \\
\hline Totally/Mostly/Somewhat agree & $53(64.7)$ \\
\hline \multicolumn{2}{|l|}{ Help us to cope with stress } \\
\hline Totally/Most/Somewhat disagree & $21(25.6)$ \\
\hline Neither agree nor disagree & $33(40.2)$ \\
\hline Totally/Mostly/Somewhat agree & $28(34.1)$ \\
\hline \multicolumn{2}{|l|}{ Tastes good } \\
\hline Totally/Most/Somewhat disagree & $0(0)$ \\
\hline Neither agree nor disagree & $0(0)$ \\
\hline Totally/Mostly/Somewhat agree & $100(100)$ \\
\hline \multicolumn{2}{|l|}{ Smells nice } \\
\hline Totally/Most/Somewhat disagree & $4(4.9)$ \\
\hline Neither agree nor disagree & $7(8.5)$ \\
\hline Totally/Mostly/Somewhat agree & $71(86.6)$ \\
\hline \multicolumn{2}{|l|}{ Looks nice } \\
\hline Totally/Most/Somewhat disagree & $3(3.6)$ \\
\hline Neither agree nor disagree & $8(9.8)$ \\
\hline Totally/Mostly/Somewhat agree & $70(85.3)$ \\
\hline \multicolumn{2}{|l|}{ Cheers up our family } \\
\hline Totally/Most/Somewhat disagree & $5(6.0)$ \\
\hline Neither agree nor disagree & $24(29.3)$ \\
\hline Totally/Mostly/Somewhat agree & $52(63.5)$ \\
\hline \multicolumn{2}{|l|}{ Is not expensive } \\
\hline Totally/Most/Somewhat disagree & $4(4.8)$ \\
\hline Neither agree nor disagree & $9(11.0)$ \\
\hline Totally/Mostly/Somewhat agree & $68(83.0)$ \\
\hline \multicolumn{2}{|l|}{ Is cheap } \\
\hline Totally/Most/Somewhat disagree & $15(18.3)$ \\
\hline Neither agree nor disagree & $19(23.2)$ \\
\hline Totally/Mostly/Somewhat agree & $48(58.6)$ \\
\hline \multicolumn{2}{|l|}{ Is good value for our money } \\
\hline Totally/Most/Somewhat disagree & $2(2.4)$ \\
\hline Neither agree nor disagree & $5(6.1)$ \\
\hline Totally/Mostly/Somewhat agree & $75(91.5)$ \\
\hline \multicolumn{2}{|l|}{ Takes no time to prepare } \\
\hline Totally/Most/Somewhat disagree & $21(25.6)$ \\
\hline Neither agree nor disagree & $13(15.9)$ \\
\hline Totally/Mostly/Somewhat agree & $48(58.5)$ \\
\hline \multicolumn{2}{|l|}{ Is low in fat } \\
\hline Totally/Most/Somewhat disagree & $12(14.6)$ \\
\hline Neither agree nor disagree & $17(20.7)$ \\
\hline Totally/Mostly/Somewhat agree & $52(63.4)$ \\
\hline
\end{tabular}




\begin{tabular}{|c|c|}
\hline \multicolumn{2}{|l|}{ Is low in calories } \\
\hline Totally/Most/Somewhat disagree & $13(15.9)$ \\
\hline Neither agree nor disagree & $20(24.4)$ \\
\hline Totally/Mostly/Somewhat agree & $49(59.7)$ \\
\hline \multicolumn{2}{|l|}{ Helps our family in weight control } \\
\hline Totally/Most/Somewhat disagree & $9(11.0)$ \\
\hline Neither agree nor disagree & $15(18.3)$ \\
\hline Totally/Mostly/Somewhat agree & $57(69.5)$ \\
\hline \multicolumn{2}{|l|}{ Is familiar to us } \\
\hline Totally/Most/Somewhat disagree & $20(24.4)$ \\
\hline Neither agree nor disagree & $15(18.3)$ \\
\hline Totally/Mostly/Somewhat agree & $41(50)$ \\
\hline
\end{tabular}

Table 3: Scores of family motivation choice between healthy weight and healthy weight children

\begin{tabular}{|c|c|c|c|}
\hline & $\begin{array}{l}\text { Healthy weight } \\
\text { (Mean } \pm \text { SD) }\end{array}$ & $\begin{array}{c}\text { Overweight/obese }^{*} \\
\text { (Mean } \pm \text { SD) }\end{array}$ & P value $^{\dagger}$ \\
\hline $\mathbf{N}$ & 40 & 42 & \\
\hline \multicolumn{4}{|l|}{ Motivation choice scores $\ddagger$} \\
\hline \multicolumn{4}{|l|}{ Health } \\
\hline Keep us healthy & $6.58 \pm 0.59$ & $6.26 \pm 1.08$ & 0.21 \\
\hline Is nutritious & $6.53 \pm 0.64$ & $6.19 \pm 1.17$ & 0.17 \\
\hline Contains a lot vitamin/minerals & $6.13 \pm 0.88$ & $5.88 \pm 1.38$ & 0.046 \\
\hline Is high in fiber & $5.05 \pm 1.45$ & $5.10 \pm 1.54$ & 0.68 \\
\hline \multicolumn{4}{|l|}{ Natural Content } \\
\hline Contains natural ingredients & $5.70 \pm 1.24$ & $5.64 \pm 1.36$ & 0.47 \\
\hline Contains no additives & $4.98 \pm 1.19$ & $5.02 \pm 1.65$ & 0.095 \\
\hline Total score for the section & $10.68 \pm 2.21$ & $10.67 \pm 2.77$ & 0.98 \\
\hline \multicolumn{4}{|l|}{ Mood } \\
\hline Help us to cope with stress & $3.50 \pm 1.60$ & $4.43 \pm 1.73$ & 0.58 \\
\hline Help us relax & $3.93 \pm 1.51$ & $4.45 \pm 1.53$ & 0.81 \\
\hline Keep us awake & $3.62 \pm 1.68$ & $3.81 \pm 1.90$ & 0.48 \\
\hline Cheers up our family & $4.87 \pm 1.30$ & $5.24 \pm 1.32$ & 0.14 \\
\hline Total score for the section§ & $15.70 \pm 4.54$ & $17.93 \pm 4.79$ & 0.03 \\
\hline Tastes good & $6.48 \pm 0.64$ & $6.48 \pm 0.60$ & 0.91 \\
\hline Smells nice & $5.80 \pm 1.16$ & $6.00 \pm 1.31$ & 0.2 \\
\hline Looks nice & $5.53 \pm 1.15$ & $5.78 \pm 1.08$ & 0.4 \\
\hline Total score for the section§ & $17.80 \pm 2.60$ & $18.12 \pm 2.89$ & 0.6 \\
\hline Food price and convenience & & & \\
\hline
\end{tabular}


Children Family Food Choice Motives among Parents of Healthy Weight and Overweight School-Aged: a Mixed Method Study

\begin{tabular}{|c|c|c|c|}
\hline Is not expensive & $5.79 \pm 1.20$ & $5.69 \pm 1.35$ & 0.58 \\
\hline Is cheap & $4.73 \pm 1.75$ & $5.12 \pm 1.47$ & 0.42 \\
\hline Is good value for our money & $6.05 \pm 0.96$ & $6.00 \pm 1.13$ & 0.5 \\
\hline Takes no time to prepare & $4.05 \pm 1.50$ & $4.74 \pm 1.47$ & 0.45 \\
\hline Total score for the section§ & $20.48 \pm 4.47$ & $21.55 \pm 3.26$ & 0.21 \\
\hline \multicolumn{4}{|l|}{ Weight control purpose } \\
\hline Is low in fat & $4.35 \pm 1.31$ & $5.17 \pm 1.45$ & 0.77 \\
\hline Is low in calories & $4.23 \pm 1.27$ & $5.02 \pm 1.52$ & 0.46 \\
\hline Helps family in weight control & $4.53 \pm 1.49$ & $5.71 \pm 1.33$ & 0.58 \\
\hline Total score for the section§ & $13.10 \pm 3.42$ & $15.90 \pm 3.91$ & 0.001 \\
\hline \multicolumn{4}{|l|}{ Familiarity } \\
\hline Is familiar to us & $4.30 \pm 1.73$ & $4.75 \pm 1.53$ & 0.26 \\
\hline Total score for the section§ & $8.54 \pm 3.19$ & $9.25 \pm 3.37$ & 0.35 \\
\hline \multicolumn{4}{|c|}{$\begin{array}{l}\text { "Weight categories were defined: } \geq 95^{\text {th }} \text { percentile, obese; } 85^{\text {th }}-94.99^{\text {th }} \text {, overweight; } 5^{\text {th }}-84.99^{\text {th }} \text { percentile, healthy weight } \\
{ }^{\dagger} \text { Differences between healthy weight children and overweight/obese children using t test } \\
{ }^{\star} \text { Score signed to the responses: Total disagree }=1 \text {, Mostly disagree }=2 \text {, Somewhat disagree }=3 \text {, Neither agree or disagree }=4 \text {, Somewhat agree }=5 \text {, } \\
\text { Mostly agree }=6 \text {, Totally agree }=7\end{array}$} \\
\hline
\end{tabular}

\section{Qualitative results}

Similar themes emerged from both parents of healthy weight and overweight/obese children when interviewed. Convenience in food preparation, price, children's taste preference and persistence in asking for unhealthy foods, and familiarity of foods consumed were the main reasons that motivated parents to decide what type of foods they would purchase and provide to their children. During the interview process, parents of overweight/obese children stated that they felt their spouses/ partners lacked support for healthy eating in the home, affecting the type of food brought into the home. However, this was not voiced among parents of healthy weight children. In addition, parents of both healthy weight and overweight children defined healthy foods as fresh fruits and vegetables and foods that have a large quantity of vitamins and minerals. However, they did not mention low-fat milk, lean proteins, or whole grains as healthy foods for their children.

\section{Convenience in food preparation}

Majority of the parents (both overweight/obese and healthy weight children) stated that they had overwhelming schedules such as children's activities and long working hours and therefore, their food choice motive was influenced by how convenient the food could be in terms of its preparation process. With this regard, they ended up buying fast foods and foods that are already prepared rather than cooking a meal at home. For example, they said: "Not enough time to cook. I am busy and I don't feel like cooking, so I will go buy fast food" and "I think it is easy to get distracted with all that is going on in the day and so sometimes it is quicker to grab something that is already prepared".

\section{Cost of food}

Majority of the parents (both healthy weight and overweight/ obese children) stated that the cost of food was their main motive when making food purchasing decisions across all socioeconomic levels. Parents often felt that healthier versions of food were more expensive, such as "Cost is a big motivator"; "Cost. Some of the foods - the good foods are expensive"; and "Healthy foods are way more expensive". One parent said that she only received a certain amount of money from Special Supplemental Nutrition Program for Women, Infants and Children (WIC)for purchasing fruits and vegetables, and she could not financially afford to replenish her food supply: "Financially, I get an \$ 8 allowance with my WIC for my son that gives me access to fruits and vegetables. I buy it and when it is gone, it's gone. We can't always replenish it". Another parent said: "I will buy because of price, first, based on our budget and we have a certain amount that we spend at the grocery store"

Nevertheless, parents felt that even though price was a major motivator when purchasing foods, providing healthy foods to their children was important and beneficial to their children's health. Following are some of the examples of what parents said:

- "My husband and I have high blood pressure so we don't want to add too much salt. So fresh is good and you can get fresh vegetables most of the time".

- "Right now I am buying for health and I am trying to buy fruits and vegetables and more healthy [foods]".

- "Basically, it is health" 


\section{Children's taste preference and changes}

It was frequently noted by parents that food purchases were influenced by what their children liked to eat and children would often ask for "junk food" regularly. Even though parents may have good intentions on having healthy foods in the home, it is evident that their children played a role in their food purchasing decisions. For example, one parent stated: "they are an influence (kids) - sometimes good; sometimes not", and another parent revealed a similar thought, "I know what foods she likes, so I usually pick those out. Her tastes sway what I buy or not buy at the store."Parent also stated that when children asked for unhealthy foods she would buy it: "The easy way out is to just buy it" and "I just don't want them to feel like anything is off limits, so I try to buy small amounts (of unhealthy foods)." Additionally, parents felt that they had to balance their food choices between what their children likes and what is healthy. For example, a parent stated: "Balance of what tastes good versus what is healthy".

Several parents (both healthy weight and overweight/obese children) felt that their children and other family members were picky eaters which made it difficult in making healthy food choices. They said: "The pickiness of everybody and it's not just the girls; my husband is picky" and "My main challenge is someone who doesn't like to eat what is made. They are picky eaters."Taste changes also influenced what a parent would bring into the home. For instance, one parent said: "She used to love fruit when she was a toddler and now she hates fruits. Its funny things like she use to like yogurt but now we are trying to get her introduced to it again; you use to like it before and it was not that long ago."

Parents also stated that eating fruits was easily accepted by children, because "of the sweet flavor", but parents had challenges in feeding children vegetables. One parent mentioned: "I think it is the taste, because vegetables are a lot harder than fruit and fruits are sweet and yummy but vegetables are different."

\section{Familiarity}

Both parents of overweight and healthy weight children also bought foods out of habit or a familiar food that they know how to prepare. For example, they mentioned the following:

- "I am kind of in a rut, so I buy the same things"

- "What they like and what I know that I can cook that they will eat. What they like, what they will eat, and what is good nutrition for them"

- "Habit is a lot of it - things that are familiar and I already know what I can do with it. You know what I mean. I already know how to prepare it, and I am less likely to choose something that I don't know what I am going to do with"

\section{Lack of support from spouses/partners for healthy eating in the home}

Parents of overweight/obese children voiced concerns over the lack of support from their spouse/partner in having healthy foods at home for their children; however, this was not expressed by parents of healthy weight children. Conflicts about what types of foods to have in the home were evident among these parents of overweight/obese children who felt that their spouses/partners did not support their family's healthy eating efforts and thus this would affect the type of food brought into the home. For instance, they mentioned:

- "Here is our biggest challenge-is that I work 60 to 70 hours a week, so a lot of time my spouse is in charge, which means going out to eat way too much".

- "I try to limit fries to once a week, although I get sabotaged by his dad. He likes the fries and he will buy the fries regardless if he has already had fries".

- "The hardest thing in the family environment is to get both parents on board and on the same page, because my wife and I don't necessarily agree on everything. I tend to be more extreme in the way I want to go and she is more lenient-you know, as far as buying things. One parent can certainly sabotage the other if you are not working together".

- "We do not have a ton of snack food and honestly, if we do, my husband brought it in, and I don't have too much control over that".

\section{Discussion}

This mixed method study provides both quantitative and qualitative results to identify and understand parental family food choice motives among healthy weight and overweight/ obese children. There were no differences between food choice motives between parents of overweight/obese and healthy weight children for the majority of subscales, except for "mood" and "weight control purposes", which indicates that regardless of children's weight status, parents had similar food choice motives (e.g., health of food, food's natural content, sensory appeal, food price and convenience, and familiarity) when feeding their children. We also found that all the parents (both parents of healthy weight and overweight children) agreed that taste of foods was an important motivation when making food choices. This is particular true for purchasing vegetables. Consistent with previous findings the parents interviewed stated that they had difficulties in getting their children to eat vegetables due to the unfavorable taste of vegetables $[14,15]$. This was not the case for fruits as parents were more likely to find that their children liked fruit's sweet taste much better than vegetable's bitter taste. Also, parents of both overweight/obese and healthy weight children stated that healthy foods were defined as foods that have sufficient vitamins and minerals which were further confirmed by our quantitative data indicating a majority of the parents of both overweight/obese and healthy weight children reported that "is nutritious" and "contains a lot of vitamins and minerals" were their primary food choice motives.

Our quantitative data showed that approximately $98 \%$ of the parents (both parents of healthy weight and overweight children) considered a food's health and nutritional value is 
important when making food choices. However, in our interviews with a subsample of participants, we found that although parents realized the importance of the health values when purchasing foods they often weighed in other factors such as food's price, the perception that healthy foods were expensive, convenience in food preparation, food's familiarity, and children's taste preference and their constant demanding for certain unhealthy "junk" foods. Therefore, parents ended up buying unhealthy foods such as high fat and sugary foods and beverages instead of healthier ones because these foods were familiar to the family and they were foods that their children preferred and asked for. A similar study involving parents of preschoolers found that parents struggled to make decisions between providing their families with healthy foods and letting their children to eat the foods they wanted which in most cases were unhealthy [15].

The majority of parents of both overweight and healthy weight children agreed with the statement "takes no time to prepare" when determining family food choice motives. When parents were interviewed, they confirmed this motive by stating that they had overwhelming schedules and their food choice motives were influenced by how convenient the food was in terms of preparation time. As a result, parents would often fed their children and family less healthier foods from fast food restaurants for quick meals. Thus, parents of both overweight/ obese and healthy weight children would benefit from nutrition education on how to make healthy meals that are easy and quick to prepare.

In addition, the total score for the subscale of "mood" was higher among parents of overweight/obese children compared to those of healthy weight children. This may suggest that enhancing mood is more relevant to parents of overweight/obese children as compared to parents of healthy weight children when purchasing and choosing foods. It may be that parents of overweight/obese children use food to help their children feel better or overcome emotions. A previous study also reported that emotional eating behaviors such as "eating when bored" or "eating when upset/ anger" were positively associated with children's BMI values [16]. However, compared to other family food choice motives, items in the "mood" subscale scored the lowest ("cheers up our family"=5.08; "helps us relax" $=4.20$ and "keeps us awake" $=3.84$ ) among all participants including parents of overweight/obese children.

In our study, parents of overweight/obese children agreed more often with the items under the subscale of "weight control purpose" (e.g., "is low in fat"; "is low in calories"; "helps family with weight control") compared to parents of healthy weight children. When further exploring parents' perceptions on this matter, parents of overweight/obese children stated that they felt their spouses or partners were not supportive with healthy eating in the home and thus this would affect the type of food brought into the home, which was not voiced by parents of healthy weight children. A previous focus group study among parents of overweight children confirmed our results and found that other family members may not be supportive in healthy eating in the home and children may be receiving conflicting messages regarding healthy eating [17]. Our finding suggest that although parents of overweight/obese children were aware of the importance of choosing food items that would help their children lose weight (e.g., "is low in fat"; "is low in calories"), family dynamics (e.g.,: other adult family members undermining the effort) could be a barrier when trying to provide healthy foods to their children. Thus, strategies such as working together as a family in the meal preparation may be helpful for bringing family members of overweight/obese children together and reaching consensus in terms of feeding children healthy foods in the home.

Our study was the first to explore food choice motives among parents of both healthy weight and overweight/obese schoolaged children using a mixed method approach. The mixed method study design not only validated the outcome data by crossreferencing responses from parents through both quantitative surveys and qualitative interviews, but also provided a deeper understanding of parental motives when making food choices, thus, giving us a clearer picture of the issues investigated [18]. Our study had limitations. Due to the relatively small sample size and convenience sampling, our results may not be generalized to the larger school-age children population in the region and the country. Although we used validated self-reported measures, objective indicators may provide more accurate evaluations of parents' motives and children's diets. However, our quantitative survey results on food choice motives were confirmed by the follow-up interviews with a subsample of parents of both healthy weight and overweight/obese children. Since our original study was designed to compare differences in food choice motives between overweight/obese and healthy weight children, we did not further examine parents' motivations across different socioeconomic statues, for example, family income and parent education background. However, our interview findings nevertheless suggest that common food choice motives such as convenience in food preparation, familiarity, food price, children's taste preference, and children consistently demanding unhealthy foods were shared among parents across different socioeconomic status.

In conclusion, our results suggest parents face some dilemma with regards to their motivations when making food choices. Although parents considered the health value of foods as an important motive, they often traded healthy foods with unhealthy foods due to other factors such as food price, convenience in preparation, familiarity, children's taste preference and their persistence in demanding certain unhealthy foods. Food choice motives related to mood and weight control appeared more relevant to parents of overweight/obese children compared to parents of healthy weight children. The current study using a mixed method approach provided a deeper understanding of parents' motivations in terms of making food choices for their children at home. 


\section{Acknowledgement}

This investigation was supported by the University of Nebraska-Lincoln Research Council Faculty Seed Grant. Nepper was also supported by a Graduate Student Research Grant as part of the Agriculture and Food Research Initiative (AFRI) Grant 2011-67002-30202 from the U.S. Department of Agriculture (USDA) National Institute of Food and Agriculture, Childhood Obesity Prevention: Trans disciplinary Graduate Education and Training in Nutrition and Family Sciences or Child Development or Related Fields to Prevent Childhood Obesity.

\section{Ethical Approval}

The study was approved by the University of NebraskaLincoln Institutional Review Board.

\section{References}

1. Kelishadi R. Childhood overweight, obesity, and the metabolic syndrome in developing countries. Epidemiol rev. 2007;29:62-76. doi: 10.1093/epirev/mxm003

2. Dietz WH. Health consequences of obesity in youth: childhood predictors of adult disease. Pediatrics. 1998;101:518-525

3. Larson N, Story M. A review of environmental influences on food choices. Ann behav med. 2009;38 Suppl 1:S56-73. doi: 10.1007/ s12160-009-9120-9

4. McKinnon RA, Reedy J, Handy SL, Rodgers AB. Measuring the food and physical activity environments: shaping the research agenda. Am J Prev Med. 2009;36(4 Suppl):S81-85. doi: 10.1016/j.amepre.2009.01.003

5. Roos E, Laaksonen M, Rahkonen O, Lahelma E, Lallukka T. Relative weight and disability retirement: a prospective cohort study. Scand J Work Environ Health. 2013;39(3):259-267. doi: 10.5271/sjweh.3328

6. Wansink B. Nutritional gatekeepers and the $72 \%$ solution. J Am Diet Assoc. 2006;106(9):1324-1327. doi:10.1016/j.jada.2006.07.023

7. Briggs L, Lake AA. Exploring school and home food environments: perceptions of 8-10-year-olds and their parents in Newcastle upon Tyne, UK. Public health nutr. 2011;14(12):2227-2235. doi: 10.1017/ S1368980011001984

8. Oellingrath IM, Hersleth M, Svendsen MV. Association between parental motives for food choice and eating patterns of 12- to 13-yearold Norwegian children. Public health nutr. 2013;16(11):2023-2031. doi: $10.1017 / S 1368980012004430$
9. Steptoe A, Pollard TM, Wardle J. Development of a measure of the motives underlying the selection of food: the food choice questionnaire. Appetite. 1995;25(3):267-284. doi: 10.1006/appe.1995.0061

10. Krebs NF, Himes JH, Jacobson D, Nicklas TA, Guilday P, Styne D. Assessment of child and adolescent overweight and obesity. Pediatrics. 2007;120 Suppl 4:S193-228. doi: 10.1542/peds.2007-2329D

11. Berge JM, Arikian A, Doherty WJ, Neumark-Sztainer D. Healthful eating and physical activity in the home environment: results from multifamily focus groups. J Nutr Educ Behav. 2012;44(2):123-131. doi: 10.1016/j.jneb.2011.06.011

12. Campbell KJ, Crawford DA, Hesketh KD. Australian parents' views on their 5-6-year-old children's food choices. Health promot int. 2007;22(1):11-18. doi: 10.1093/heapro/dal035

13. Creswell JW. Educational research: Planning, conducting, and evaluating quantitative and qualitative research. 5th ed. Pearson; 2015.

14. Dwyer J, Needham L, Simpson JR, Heeney ES. Parents report intrapersonal, interpersonal, and environmental barriers to supporting healthy eating and physical activity among their preschoolers. Appl Physiol Nutr Metab. 2008;33(2);338-346. doi: 10.1139/H07-195

15. Vanhala ML, Laitinen J, KaikkonenK, Keinanen-Kiukaanniemi S, Korpelainen R. Parental predictors of fruit and vegetable consumption in treatment-seeking overweight children. J Hum Nutr Diet. 2011;24(1),47-53. doi: 10.1111/j.1365-277X.2010.01133.x

16. Hajna S, LeBlanc P, Faught B, Merchant A, Cairney J, Hay J, et al. Associations between family eating behaviours and body composition measures in per-adolescents: Results from a community-based study of school-aged children. Canadian Journal of Public Health, 2014;105(1):e15-e21.

17. Sonneville KR, LaPelle N, Taveras EM, Gillman MW, Prosser L A Economic and other barriers to adopting recommendations to prevent childhood obesity: results of a focus group study with parents. BMC Pediatrics. 2009;9:81.

18. Pearce A, Kirk C, Cummins S, Collins M, Elliman D, Connolly AM, et al. Gaining children's perspectives: a multiple method approach to explore environmental influences on healthy eating and physical activity. Health place. 2009;15(2):614-621. doi: 10.1016/j. healthplace.2008.10.007 